\title{
Processing and Wear Behaviour of 3D Printed PLA Reinforced with Biogenic Carbon
}

\author{
Ertan G. Ertane, ${ }^{1}$ Annett Dorner-Reisel $\left(D,{ }^{1}\right.$ Ozlem Baran, ${ }^{2}$ \\ Thomas Welzel, ${ }^{3}$ Viola Matner, ${ }^{1}$ and Stefan Svoboda ${ }^{4}$ \\ ${ }^{1}$ University of Applied Sciences Schmalkalden, Faculty of Mechanical Engineering, 98574 Schmalkalden, Germany \\ ${ }^{2}$ Erzincan University, Faculty of Mechanical Engineering, 24100 Erzincan, Turkey \\ ${ }^{3}$ Thüringisches Institut für Textil- und Kunststoff-Forschung e. V., 07407 Rudolstadt, Germany \\ ${ }^{4}$ University of Applied Sciences Schmalkalden, Faculty of Electrical Engineering, 98574 Schmalkalden, Germany
}

Correspondence should be addressed to Annett Dorner-Reisel; a.dorner-reisel@hs-sm.de

Received 31 January 2018; Revised 15 May 2018; Accepted 29 May 2018; Published 1 August 2018

Academic Editor: Umar Nirmal

Copyright (C) 2018 Ertan G. Ertane et al. This is an open access article distributed under the Creative Commons Attribution License, which permits unrestricted use, distribution, and reproduction in any medium, provided the original work is properly cited.

\begin{abstract}
For the first time, biocarbon reinforced polylactide (PLA) filaments were available for the 3D printing. Biocarbon is the carbon obtained from trees, plants, and soils to naturally absorb and store carbon dioxide from the atmosphere. One of the most important features is renewability. Because of this, it has been decided to reinforce PLA with biocarbon to obtain $100 \%$ recyclable material. Although PLA has been used in 3D printing for a long time, more applications like housings or structural interior of automobiles or other vehicles can be realised, if the mechanical and tribological properties are improved. Because the new PLA/biocarbon reinforced composites are degradable, they can be used as soil improvement after end of life as a structural material. The filaments were produced by compounding the biocarbon with polylactide granulate. Biocarbon was produced by pyrolysis of wheat stems at $800^{\circ} \mathrm{C}$. The biomass were collected from different regions in Germany, Europe. As shown by Raman spectroscopy, the in-plane crystallite size of pyrolysed wheat stems from different regions is almost similar and amounts to $2.35 \pm 0.02 \mathrm{~nm}$. Biocarbon particles were successfully integrated into the polylactide. Filaments of $1.75 \mathrm{~mm}$ diameter were produced for 3D (3-dimensional) printing. Filaments with 5 vol.- $\%, 15$ vol.- $\%$, and 30 vol.- $\%$ biocarbon were extruded. The fused deposition modelling (FDM) printing process was slightly hindered at higher biocarbon loading. Based on optical and scanning electron microscopy, a very homogeneous particle distribution can be observed. Single carbon particles stick out of the filament surface, which may be a reason for enhanced nozzle wear during 3D printing. Friction is more stable for 30 vol.- $\%$ reinforced PLA in comparison to unreinforced PLA and composites with lower particle fraction. This effect could be caused by some topographical effects due to void generation at the surface of PLA with 30 vol.- $\%$ biocarbon. In general, the tribological resistance increases with higher volume fraction of biocarbon.
\end{abstract}

\section{Introduction}

Polylactide acid (PLA) is considered as one of the best substitutes for petroleum-based polymers [1]. It is a biodegradable polymer from renewable resources. Not only can polymer waste pollution be reduced by easy degradation, but advantageous optical, chemical, and sufficient mechanical properties also make PLA a requested material for packaging, food, and biomedical applications [2-5]. Further improvement of the PLA properties, like adjusted thermal conductivity or increased strength, can be achieved by reinforcement with particles and fibres [6-10]. PLA composites with sophisticated mechanical behaviour and durability reach a high interest in automotive, aviation, and aerospace applications $[11,12]$. In the present study, carbon from biomass pyrolysis is used as reinforcement for PLA.

Objective is to produce composites completely from renewable resources, which have improved tribological attributes. The reinforced PLA parts should be used a second time after end of life. Finishing the operation as structural material, components may be chopped and function as soil conditioner by simple self-degradation.

In this stage of application, the special features of the reinforcement should come to useful application. It is known that biochar improves soil quality by keeping an efficient level 
TABLE 1: Origin of the biomass (wheat stems) for producing biocarbon by slow pyrolysis at $800^{\circ} \mathrm{C}$.

\begin{tabular}{lcccc}
\hline sample & city/region & \multicolumn{2}{c}{ geographic origin in Europe } \\
& Kap Arkona & localisation & country & continent \\
\hline biocarbon 1 & Schmalkalden & Pomerania & Germany, central & Europe \\
\hline biocarbon 2 & Jena & Thuringia & Germany, central & Europe \\
\hline biocarbon 3 & Gera & Thuringia & Europe \\
\hline biocarbon 4 & & Thuringia & Eermany, central & \\
\hline
\end{tabular}

of minerals, useful ions, nutrients, and water for enabling rich plant growth [13-15]. It reduces soil degradation [13] which is a major global problem. Biochar is a highly carbonaceous charred material obtained from biomass by heat treatment. Top temperatures of biomass conversion for gaining biochar are up to $700^{\circ} \mathrm{C}$ mostly $[16,17]$. Vacuum pyrolysis has been extensively applied for biomass conversion [13, 18]. It is especially advantageous that vacuum pyrolysis yields gaseous, liquid, and solid products. If the top temperatures of pyrolysis are increasing, biochar gradually converts into biocarbon by ongoing splitting off more gaseous products $[19,20]$. The top temperatures for biocarbon production can differ considerably from $800^{\circ} \mathrm{C}$ to above $2000^{\circ} \mathrm{C}$. It depends on the desired carbonaceous or carbon microstructure. In the present study, enough soil stimulation is required. Therefore, a low pyrolysis temperature of just $800^{\circ} \mathrm{C}$ was selected. It results in sufficient crystallinity [21]. The last is necessary for satisfactory mechanical-tribological effects in the envisaged structural applications of the composite. They should obtain sophisticated properties in comparison to mere polylactide, made completely from natural source. Therefore they have the capability to degrade easily and are non-harmful to the environment.

Although, after application as structural material, a downcycling for applications as soil conditioner in agriculture is envisaged, the first steps are production and testing of the biocomposite. In the present study, newly created composite filaments from PLA and biocarbon are introduced. They were further processed by the $3 \mathrm{D}$ printing method Fused Deposition Modelling (FDM). As shown by several researchers [22-24] before, reinforcement with particles or fibres can effect considerable improvement of wear resistance, if optimised processing parameters are chosen. The present work aims to study tribological properties of the completely biogenic hybrid material: PLA with biocarbon reinforcement. Correlations are drawn to the structure of biocarbon, as well as to the processing technique FDM.

\section{Experimental Methods}

2.1. Processing of Biogenic Carbon Pyrolysis. Biocarbon was produced by pyrolysis of wheat stems. Biomass samples of wheat stems from five different regions in Germany, Europe, were collected (Table 1). The biomass samples were pyrolysed in a high vacuum oven of the company THERMAL TECHNOLOGY GmbH, Germany. The ground material, which has been chopped, was weighed into ceramic boats and heated up to top temperature of $800^{\circ} \mathrm{C}$ for 2 hours holding. Usually, Biochar for soil improvement is pyrolysed up to $700^{\circ} \mathrm{C}$ maximum top temperature. There are still sufficient functional groups at this top temperature. Biochar properties like ammonium and nitride adsorption are correlated to the presence of sufficient functional groups. In the present study, a slightly higher pyrolysis temperature of $800^{\circ} \mathrm{C}$ was chosen, because sufficient crystallinity is essential for structural application as well. Fraction and size of crystalline carbon in comparison to amorphous carbon are growing with heat treatment top temperatures. Pyrolysis temperature should not be too high, in order to find a satisfying balance between good crystallinity for tribological application and sufficient fraction of functional groups for soil improvement after downcycling the structural part at the end of life.

2.2. Characterisation of Biogenic Carbon. The biocarbons are characterised by Raman spectroscopy. All Raman spectroscopy measurements were performed with a Renishaw inVia Raman spectrometer. Following switching on the spectrometer and run-in for 30 minutes, silicon reference sample was used to control the accuracy of the measurement.

After positioning of the sample, the surface of pyrolysed biocarbon was investigated by applying a 50x magnification. Exact position can be checked, if the laser was in centre point. The setting parameters for the measurement were as follows: range of $100-3200 \mathrm{~cm}^{-1}$, exposure time of $10 \mathrm{~s}$, laser power of $1 \%$, and accumulations of 50 . Every measurement was carried out with a $532 \mathrm{~nm}$ laser diode in backscattering configuration. For evaluation of the Raman spectra, a simple twosymmetric-line fit ( $\mathrm{D}$ and $\mathrm{G}$ bands) with linear background (baseline) correction was performed.

\subsection{Biocarbon Reinforced Polylactide (PLA) for $3 D$ Printing.} For the first time, biocarbon reinforced PLA filaments were available for the $3 \mathrm{D}$ printing. The filaments were produced by compounding the biocarbon with polylactide granulate. Commercial PLA grade, Luminy ${ }^{5}$ LX175 biopolymer (Corbion N.V., Netherlands), was selected. Mechanical properties of this biopolymer are summarized in Table 2 .

3-dimensional (3D) printing is a method used to produce $3 \mathrm{D}$ geometries due to a layer by layer or segment by segment technique which is based on computer aided design (CAD) models [25]. Various printing techniques have been developed to produce 3D physical models. Generally, methods such as fused deposition modelling, selective laser sintering, stereolithography inkjet, and 3D printing are preferred. The choice of the production technique depends on the starting materials, the processing speed, and resolution requirements as well as on the cost and performance requirements of 


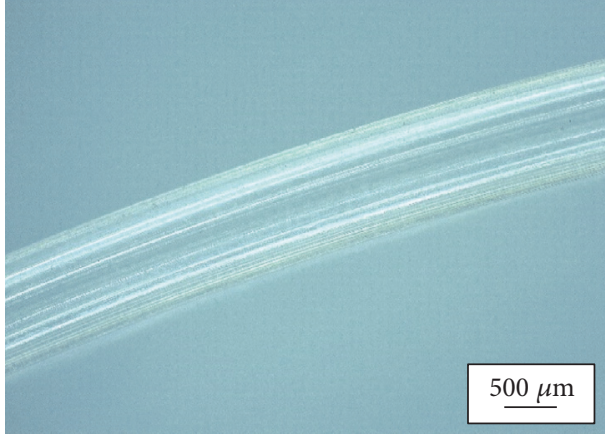

(a)

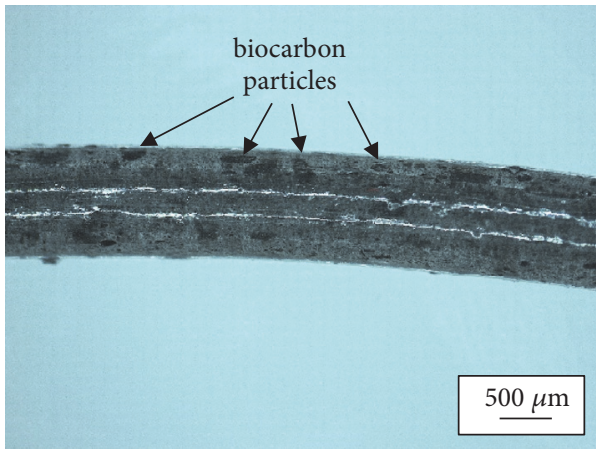

(c)

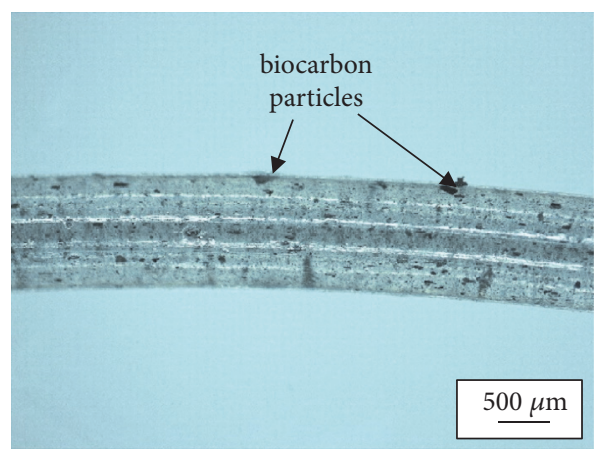

(b)

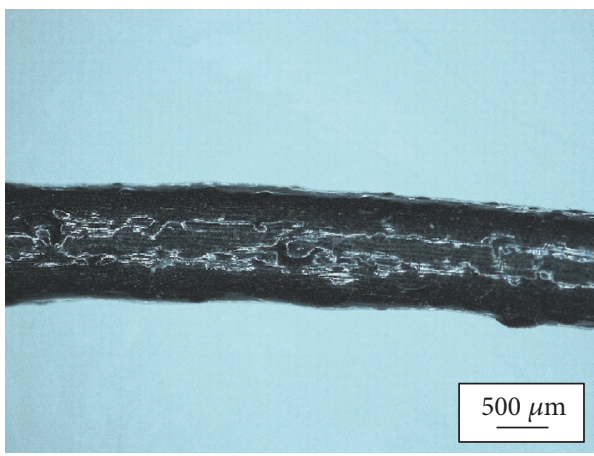

(d)

FIGURE 1: Stereomicroscopic images of the filaments: (a) unreinforced PLA, (b) PLA with 5 vol.-\% biocarbon, (c) PLA with 15 vol.-\% biocarbon, and (d) PLA with 30 vol.-\% biocarbon.

TABLE 2: Typical material properties of polylactide matrix biopolymer (Luminy LX175, N.V., Netherlands).

\begin{tabular}{lc}
\hline Melting temperature & $155^{\circ} \mathrm{C}$ \\
\hline Glass transition temperature & $55-60^{\circ} \mathrm{C}$ \\
\hline Tensile yield strength & $45 \mathrm{MPa}$ \\
\hline Tensile elongation & $\max .5 \%$ \\
\hline Tensile modulus & $3500 \mathrm{MPa}$ \\
\hline
\end{tabular}

the final products. Thus, each technique has advantages and disadvantages [26]. For FDM, adjustable porosity and low processing temperatures, as well as relative low cost, are favourable.

Reinforcements can considerably alter and improve properties of polymer composite produced by 3D printing. Besides, deposition layer thickness, temperature of liquefaction, compartment spacing and printing speed have also been proven to influence the mechanical properties of reinforced PLA composites [27].

In the present study, reinforced PLA filaments for the $3 \mathrm{D}$ printing were produced by compounding the biocarbon with polylactide. Biocarbon powders were added to PLA at the 3 different ratios (5 vol.- $\%, 15$ vol.- $\%$, and 30 vol.- $\%$ ) to produce reinforced PLA filaments of $1.75 \mathrm{~mm}$ diameter (Figures 1(a)-1(d)). Filaments were produced by polymer extrusion. Following filament production, CAD designs were drawn in SolidWorks software (Dassault Systems SolidWorks Corp., USA).

Then the design data were saved as a standard template library (STL) file for the $3 \mathrm{D}$ printer and transferred to $3 \mathrm{D}$ printable format using the Simplify3D software (Simplify3D LLC, USA).

For tribological tests, cylindrical pieces with a diameter of $24 \mathrm{~mm}$ and a thickness of $7.8 \mathrm{~mm}$ (Figure 2) with the same dimensions were printed using the above-mentioned filaments. The maximum build volume of the $3 \mathrm{D}$ printer was $20 \times 20 \times 20 \mathrm{~cm}$ (length, width, and height, respectively) with a nozzle opening diameter of $0.4 \mathrm{~mm}$. The nozzle material is brass. Models were formed from solid layers on the bottom, top, and sides, but the inner mesh was filled with 10 percent only. A nozzle extrusion temperature of $220^{\circ} \mathrm{C}$ was used, while the heat bed temperature amounted to $80^{\circ} \mathrm{C}$. Samples were printed with a layer high of $0.30 \mathrm{~mm}$, deposition line width $0.33 \mathrm{~mm}$, and good quality aiming to obtain the highest printing resolution. Approximately $70 \mathrm{~cm}$ filament was used to produce each sample. The nozzle has clogged occasionally. This was observed during printing of 30 vol.-\% biogenic carbon reinforced PLA especially. In future, this problem can be solved, if a larger diameter nozzle or wear resistant coatings on the nozzle surface are used.

2.4. Tribological Tests. Wear resistance of the 3D printed cylinders was investigated using the translatory oscillation apparatus SRV-III of the company Optimol GmbH Munich, 


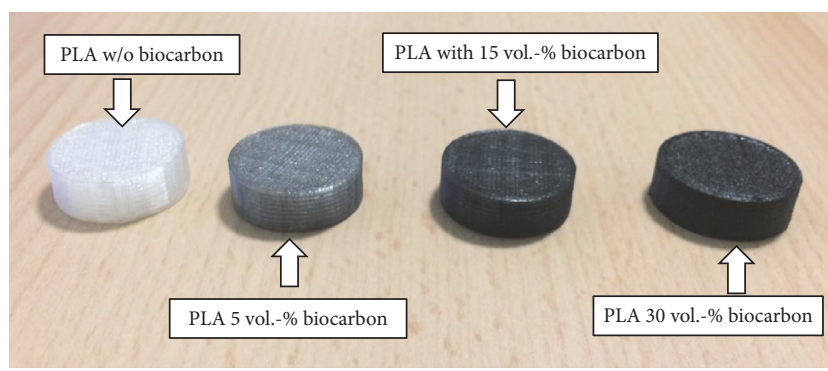

(a)

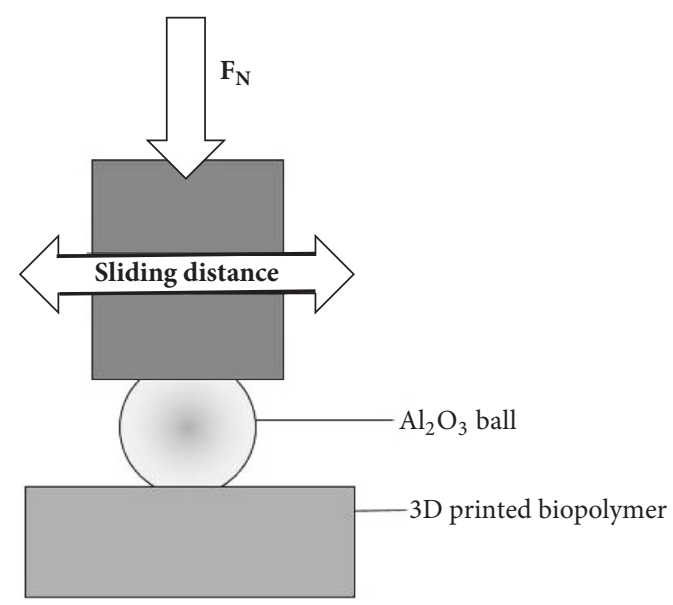

(b)

FIGURE 2: (a) 3D printed biopolymers with different biocarbon content for tribological tests. (b) Set up for tribological tests.

Germany. The 3D printed cylinders (Figure 2(a)) were tested at about $20^{\circ} \mathrm{C}\left( \pm 0.2^{\circ} \mathrm{C}\right)$ and $40 \%( \pm 2 \%)$ relative humidity using sliding in the linear reciprocating mode with a stroke length (sliding distance) of $1000 \mu \mathrm{m}$. The counterbody was an $\mathrm{Al}_{2} \mathrm{O}_{3}$ ball with $10 \mathrm{~mm}$ diameter (Figure 2(b)). Wear tests were carried out without lubricant (dry condition). A normal load of $1 \mathrm{~N}$ was applied for a testing time of 150 minutes. Before testing, the surface of the ball was cleaned with alcohol. Tests were performed in close relation to the standard DIN 51834-Part 1. The mentioned standard describes the test and calculation methods for the high-frequency linear oscillation test machine to determine tribological quantities such as friction and wear. The wear volume was determined by measurements with Confocal Laser Scanning Microscopy CLSM (LSM 700 laser scanning microscope, Carl Zeiss Microscopy GmbH, Germany).

For determining wear volumes with CLSM, the upper level and the bottom level were define. Acquisition of a $3 \mathrm{D}$ topographic image is achieved by the movement of the objective lens along the vertical axis. During this process, a number of successive 2D images was collected at evenly spaced height levels. The step height is defined as the vertical distance between two successive optical slices. It can be manually set. Owing to the high precision of the $\mathrm{Z}$-axis drive, the step height can be as small as $10 \mathrm{~nm}$. For big wear traces, the number of steps would be very high by applying small step height. In the present study, every wear trace topography was measured with a number of 60 steps (slices). Every wear trace was measured 3 times.

\section{Results and Discussion}

3.1. Biogenic Carbon Characterisation. The biocarbon is tested by Raman spectroscopy. It is very sensitive to structural changes of carbons. Graphite belongs to the space group $\mathrm{D}^{4}{ }_{6 \mathrm{th}}$. It has a strong binding within the graphitic carbon hexagons with small nearest-neighbour separation of 0.1421 $\mathrm{nm}$. The large interlayer distance of $0.335 \mathrm{~nm}$ is the reason for weak binding between graphitic layers.
Raman spectrum of highly oriented pyrolytic graphite (HOPG) exhibits the $\mathrm{E}_{2 \mathrm{~g}}$ mode around $1582 \mathrm{~cm}^{-1}$ only [28]. It is called G-band because the letter " $G$ " indicated the graphitic origin. The G-band can be found in every carbon material with $\mathrm{sp}^{2}$-hybridised C-C bindings. It is not necessarily caused by aromatic carbon rings only but by any $\mathrm{sp}^{2}$ hybridised C$\mathrm{C}$ bindings. The laser excitation causes a stretching of the $\mathrm{sp}^{2}$-hybridised C-C bindings. Therefore this Raman mode is also called "stretching mode." For disordered polycrystalline carbon with aromatic rings of $\mathrm{sp}^{2}$-hybridised $\mathrm{C}-\mathrm{C}$ bindings, besides the G-band, a band around $1350 \mathrm{~cm}^{-1}$ appears. It is called D band. The letter " $\mathrm{D}$ " stands for disorder. This band is caused by disordered aromatic graphite rings.

Biogenic carbons were characterised by Raman spectroscopy. Ferrari and Robertson [29] suggest that, at small values of in-plane crystallite size, the $\mathrm{D}$ band intensity is proportional to the probability to find mainly sixfold aromatic $\mathrm{C}-\mathrm{C}$ rings in the establishing short-range order of crystalline carbon. They explain that at small $\mathrm{L}_{\mathrm{a}}$ the $\mathrm{D}$ band strength is proportional to the probability of finding aromatic sixfold $\mathrm{C}-\mathrm{C}$ rings in the carbon cluster in relation to the whole defective in-plane crystallite area $L_{a}$, as small in-plane crystallite sizes $L_{a}$ values around or mainly below $2 \mathrm{~nm}$ are included.

Matthews et al. [30] suggest considering the dependency of $\mathrm{D}$ and $\mathrm{G}$ bands intensities on changing laser wavelength. $\mathrm{C}\left(\lambda_{\mathrm{L}}\right)$ is a wavelength dependent prefactor. Because, in the present study, a laser wavelength of $532 \mathrm{~nm}$ was used, the following relation (1) according to Matthews et al. [30] was applied for calculating the in-plane crystallite size $\mathrm{L}_{\mathrm{a}}: \mathrm{C}\left(\lambda_{\mathrm{L}}\right)$ $\approx \mathrm{C}_{0}+\lambda_{\mathrm{L}} \mathrm{C}_{1}$, with $\mathrm{C}_{0}=-12.6 \mathrm{~nm}$ and $\mathrm{C}_{1}=0.033$, valid for 400 $\mathrm{nm}<\lambda_{\mathrm{L}}<700 \mathrm{~nm}$.

$$
\frac{I_{D}}{I_{G}}=C\left(\lambda_{L}\right) L_{a}^{2}
$$

$\mathrm{I}_{\mathrm{D}}$ : D-peak intensity of Raman spectrum

$\mathrm{I}_{\mathrm{G}}$ : G-peak intensity of Raman spectrum 
TABLE 3: Results from Raman spectroscopy, $532 \mathrm{~nm}$ laser wave length.

\begin{tabular}{lcccc}
\hline sample & D-peak position & G-peak position & Intensity ratio $\mathbf{I}_{\mathbf{D}} / \mathbf{I}_{\mathbf{G}}$ & $\mathbf{L}_{\mathbf{a}}{ }^{*} / \mathbf{n m}$ \\
\hline biocarbon 1 & 1345.9 & 1595.6 & 0.91 & 2.331 \\
\hline biocarbon 2 & 1340.0 & 1596.1 & 0.89 & 2.363 \\
\hline biocarbon 3 & 1338.0 & 1595.3 & 0.91 & 0.88 \\
\hline biocarbon 4 & 1340.0 & 1599.0 & 0.90 & 2.375 \\
\hline mean value & 1341.0 & 1596.5 & 0.02 & 2.375 \\
\hline standard deviation & 3.4 & 1.7 & 0.02 \\
\hline
\end{tabular}

${ }^{*}$ ) $\mathrm{L}_{\mathrm{a}}$ : in-plane crystallite size after pyrolysis at $800^{\circ} \mathrm{C}$.

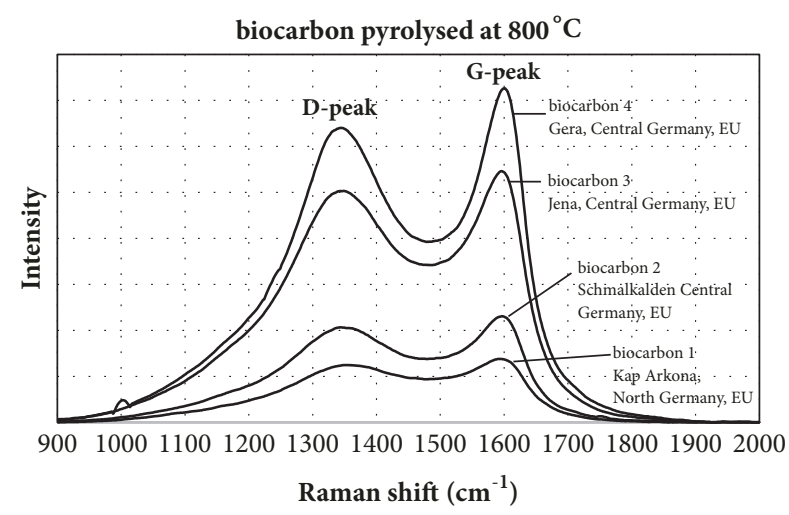

FIGURE 3: Raman spectra of biocarbons from wheat stems of different regions in Germany.

\section{$\lambda_{\mathrm{L}}$ : laser wavelength \\ $\mathrm{C}\left(\lambda_{\mathrm{L}}\right)$ : wavelength dependent prefactor \\ $\mathrm{L}_{\mathrm{a}}$ : in-plane crystallite size}

The determined in-plane crystallite sizes are between 2.331 and $2.375 \mathrm{~nm}$ (Table 3, Figure 3). As these data are slightly above $2 \mathrm{~nm}$ in-plane crystallite size, they should be considered with some caution. Zickler et al. [31] present Raman data from pyrolysed wood and observed changes of FWHM of D and G bands. They pronounce influences of laser power, sample preparation, and particularly the detailed microstructure of different carbons derived from wooden biomass. The fraction of cellulose, hemicellulose, and lignin can have different influence on the structural transformation during thermal treatment as well [32]. Cellulose decreases the content of smaller aromatic ring structures with 3-5 rings, resulting in an increase of order. The addition of hemicellulose or lignin promoted the content of smaller aromatic structures with more edges and subsequently disorder. Azargohar et al. [33] report about an $\mathrm{I}_{\mathrm{D}} / \mathrm{I}_{\mathrm{G}}$ ratio of 1.88 for biochar from wheat stems which were thermally treated at $550^{\circ} \mathrm{C}$. Such a high $\mathrm{I}_{\mathrm{D}} / \mathrm{I}_{\mathrm{G}}$ ratio indicates high concentrations and/or size of aromatic defect-rich clusters. Shao et al. [34] observe an $I_{D} / I_{G}$ ratio of around 0.5 after slow pyrolysis of wooden lignocellulose at approximately $500^{\circ} \mathrm{C}$. With increasing pyrolysis temperature, the $\mathrm{I}_{\mathrm{D}} / \mathrm{I}_{\mathrm{G}}$ ratio increases due to the ongoing transformation of amorphous carbon into crystalline aromatic defect-rich islands. At around $800^{\circ} \mathrm{C}$ pyrolysis temperature, the $\mathrm{I}_{\mathrm{D}} / \mathrm{I}_{\mathrm{G}}$ ratio amounts to 0.65 approximately according to Shao et al. [34]. In comparison to Shao et al., in the present study, the $\mathrm{I}_{\mathrm{D}} / \mathrm{I}_{\mathrm{G}}$ ratios of the wheat stem driven biocarbons pyrolysed at $800^{\circ} \mathrm{C}$ are higher. However, all wheat stem samples show almost equal $\mathrm{I}_{\mathrm{D}} / \mathrm{I}_{\mathrm{G}}$ ratios between 0.88 and 0.90 (Table 3 ). The minor differences between the $\mathrm{I}_{\mathrm{D}} / \mathrm{I}_{\mathrm{G}}$ ratios of wheat stem based biomasses from different regions give evidence of a reliable carbon-source with homogeneous biogenic microstructure. Due to the fact that there is no significant difference of $\mathrm{I}_{\mathrm{D}} / \mathrm{I}_{\mathrm{G}}$ ratios, it can be concluded that the used biomasses had almost the same fractions of lignin, cellulose, and hemicellulose, and the parameters of pyrolytic processing stay very equal in different oven runs. Biocarbons from the mentioned different planting locations (Table 1) were mixed together and used as one batch for reinforcing the PLA.

3.2. Fused Deposition Modelling of PLA Reinforced with Biocarbon. As mentioned before, the printability by the fused deposition modelling FDM is influenced by the fraction of biocarbon. Especially, at high loading with biocarbon particles of 30 vol.- $\%$, the used nozzle was clogged from time to time. The carbon particles were not molten nor plasticized like the biopolymer PLA during passing the nozzle. Biocarbon particles stay solid and unchanged during transport through the nozzle mostly.

To a certain extent, one can expect an upgraded pressing in and improved embedding of the particles in the polylactide matrix due to the heat treatment in the nozzle. Scanning electron microscopy gives evidence of a close contact between the biocarbon particles and the polylactide matrix after printing (Figure 4). There are no micro-crevices visible at the interface between particles and polylactide. The PLA surrounds the biocarbon particles completely giving evidence of a good mechanical interlocking.

The surfaces of the 3D printed samples differ a lot in dependence on the fraction of biocarbon (Figures 5-8). There are oval and roundish voids visible, if there is any biocarbon reinforcement. The amount of voids is increasing with enhanced volume fraction of biocarbon (Figures 6 and 7), while unreinforced PLA shows almost no surface blowhole (Figure 5) after FDM processing.

These findings are in consensus with the results of Kariz et al. [22]. They investigated the effect of wood addition in $3 \mathrm{D}$ printing of polylactide. Kariz et al. observed also that with increasing fraction of reinforcement the filament surface becomes rougher. Voids developed in $3 \mathrm{D}$ printed parts. 


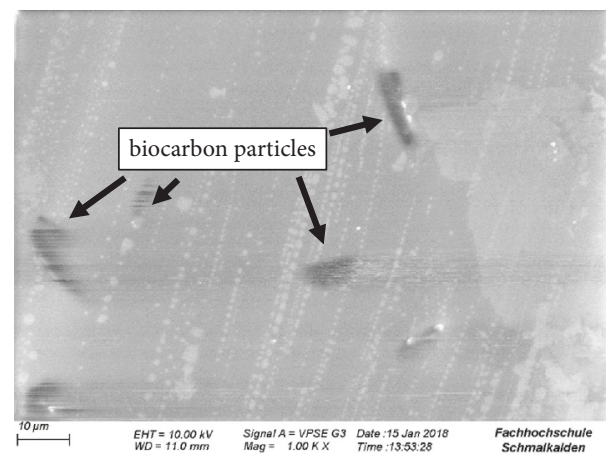

FIGURE 4: Biocarbon particles in polylactide matrix, and PLA with 30 vol.- $\%$ biocarbon, SEM.

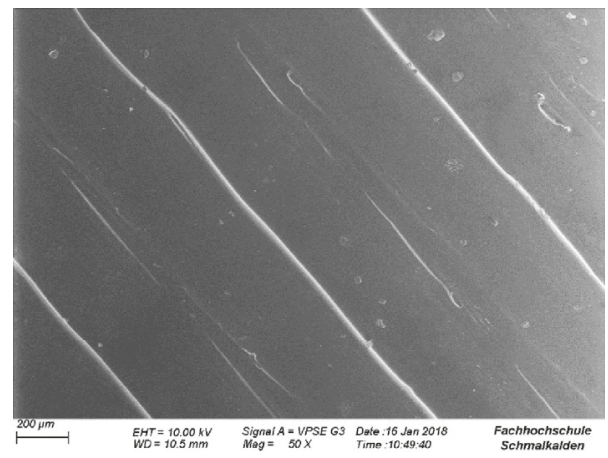

FIGURE 5: Surface of PLA after 3D printing by FDM technology, SEM.

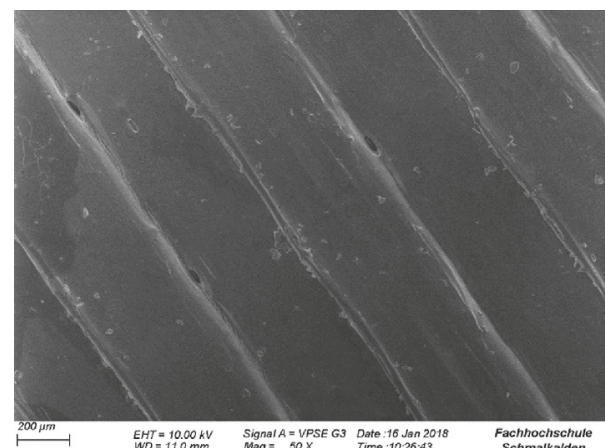

FIGURE 6: Surface of PLA with 15 vol.-\% biocarbon after 3D printing by FDM technology, SEM.

Nozzle clogging occurred during FDM at higher fraction of reinforcement. The FDM process parameters are almost similar to the process parameters which were used in the present study. The printing temperature according to Kariz et al. was $230^{\circ} \mathrm{C}$. The nozzle had an opening of $0.4 \mathrm{~mm}$. Layer thickness amounted to $0.19 \mathrm{~mm}$ which is lower in comparison to the present work.

\subsection{Tribological Tests}

3.3.1. Evaluation of the Wear Mechanisms. The worn surface of polylactide without biocarbon is shown in Figure 9. As

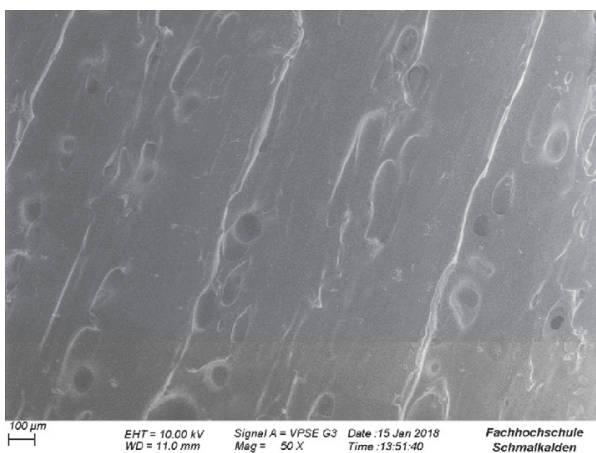

FIGURE 7: Surface of PLA with 30 vol.-\% biocarbon after 3D printing by FDM technology, SEM.

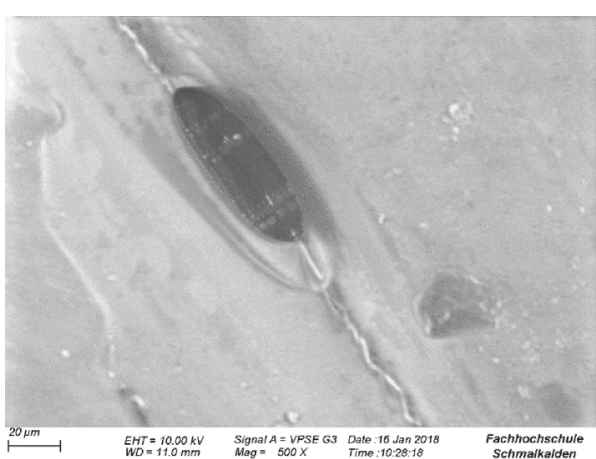

FIGURE 8: Surface of PLA w/o biocarbon after 3D printing by FDM technology, SEM.

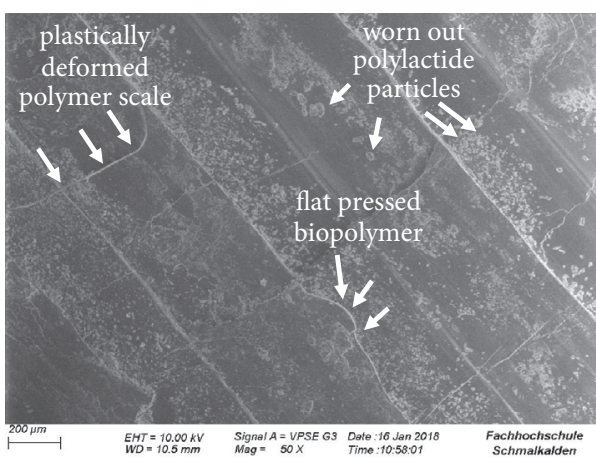

FIgURE 9: Polylactide PLA w/o biocarbon, SEM.

visible, the deformed rows of filaments sustain in shape almost after the wear test, although polylactide has a very low impact strength and low maximum service temperature. The unreinforced polylactide is deformed to some extent plastically under the periodic sliding of the alumina counterbody. Edges of material scales are visible in the worn surface. A proper plastic deformation is seen in the wear trace of PLA with 5 vol.-\% biocarbon as well (Figure 10). There are wrinkled segments. A higher crack density is evident in the wear cracks of PLA with 5 vol.- $\%$ biocarbon in comparison to unreinforced PLA after the wear test. 


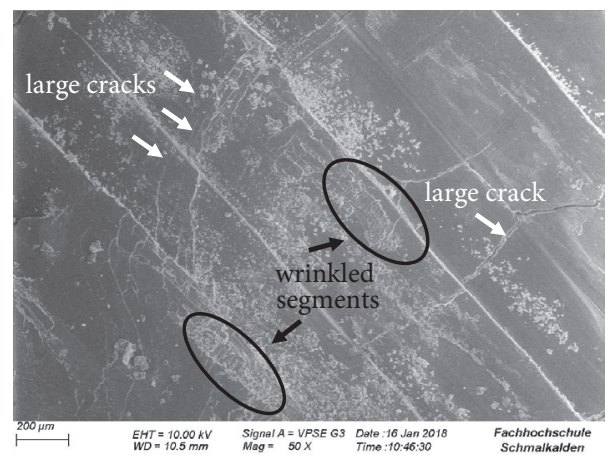

FIgURe 10: Polylactide PLA 5 vol.-\% biocarbon, SEM.

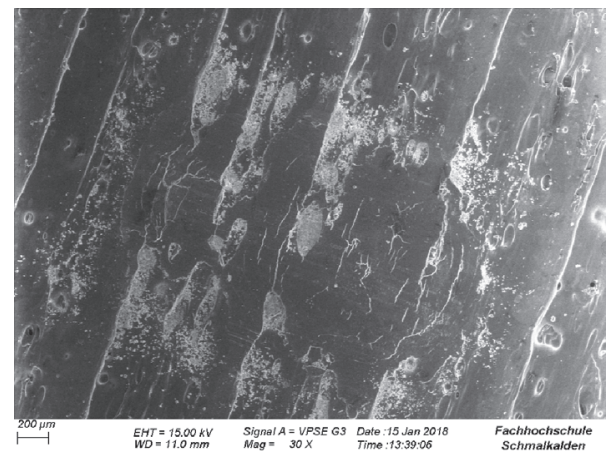

Figure 11: Polylactide PLA 30 vol.-\% biocarbon, SEM.

PLA with 30 vol.-\% biocarbon reveals a different appearance of the worn surface (Figure 11). The before mentioned oval and roundish voids are still visible. There was no healing by smearing in these voids due to the cyclic sliding of the alumina ball, but voids are filled by sticking wear particles. This observation points to the fact that the contact and loading conditions did not lead to crucial heat development which would cause plastic flow of the thermoplastic followed by deformation of these oval voids. However, the voids originated by the $3 \mathrm{D}$ printing process still have sharp edges with no sign of plastic flow due to heat impact during periodic sliding. As mentioned before, the voids are filled with smaller worn out particles. The worn surface of the unreinforced PLA and the PLA with 5 vol.- $\%$ or 15 vol.- $\%$ biocarbon is covered by wear particle more or less homogeneously. On the worn surface of PLA reinforced with 30 vol.-\% biocarbon seems to be less polymeric wear debris. They are captured in the multitude of oval surface blowholes.

There are cracks in all samples either with or without biocarbon reinforcement after tribological tests (Figures 9-12). Long cracked lines of roundish contour are evident in the PLA without and low volume fraction of reinforcement.

Under impact of the normal force which is acting on the sliding alumina ball, the biopolymer is loaded by bending periodically. It deforms stepwise stronger during ongoing energy accumulation. Cracks develop when deformability of the material is exceeded leading to observed enormous large crack circles (Figure 10).

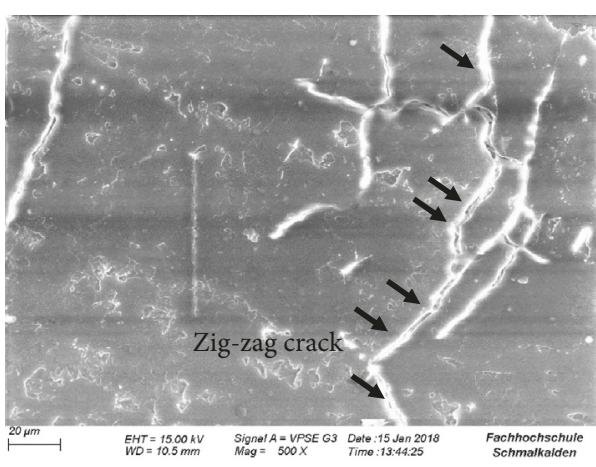

Figure 12: Polylactide PLA 30 vol.-\% biocarbon: Zig-zag cracks, SEM.

Young's modulus of unreinforced and biocarbon reinforced filaments was determined according the standard DIN EN ISO 5079:1996-02. An average increase of stiffness for the reinforced filaments of $8 \%$ was measured in comparison to the unreinforced PLA. The unreinforced PLA filament has Young's modulus of $1.083 \mathrm{GPa}$, while an average value of 1.169 GPa was calculated for reinforced filaments. A dependency on the volume fraction of biocarbon was not experimentally proven at this stage. However, this may be caused due to the low number of single filaments required for testing according the standard DIN EN ISO 5079:1996-02, which is only 8 filaments for each filament type.

With biocarbon reinforcement, the stiffness of the samples increases. This results in less elastic deflection, reduced correlated stresses, and deformation and materials fatigue in the reinforced PLA and, subsequently, there are less roundish large cracks in the sample with 15 vol.- $\%$ and 30 vol.- $\%$ biocarbon.

In addition to these large cracks, there are smaller cracks with zig-zag shape. These cracks are not observable in unreinforced polylactide but seem to grow in number with the volume fraction of biocarbon. The most zig-zag cracks are observed in PLA with 30 vol.-\% biocarbon (Figure 12). While roundish larger cracks expand to millimetres, zig-zag cracks are just some 10 micrometres in dimension. One needs to take into consideration that there is higher material stiffness but a lower elongation for the reinforced bioplastic in comparison to the unreinforced PLA. The later has a tensile elongation of $3.5 \%$ (Table 2). Carbon materials have an elongation of about an order of magnitude lower. The biocomposites become stiffer, but more brittle with reinforcement. This may be a reason for a change of the ratio of the two basic wear mechanisms: (a) fatigue wear and (b) abrasive wear. The abrasive wear is scratching due to the alumina ball surface topography and additional microcracking, if brittleness increases.

3.3.2. Wear Volume. The morphology of the worn surfaces was obtained from Confocal Laser Scanning Microscopy CLSM. For polylactide w/o biocarbon, polylactide with 5 vol.-\% biocarbon, polylactide with 15 vol.-\% biocarbon, and polylactide with 30 vol.- $\%$ biocarbon the CLSM pictures are shown in Figures 13(a)-13(d). Data of wear volumes of the 


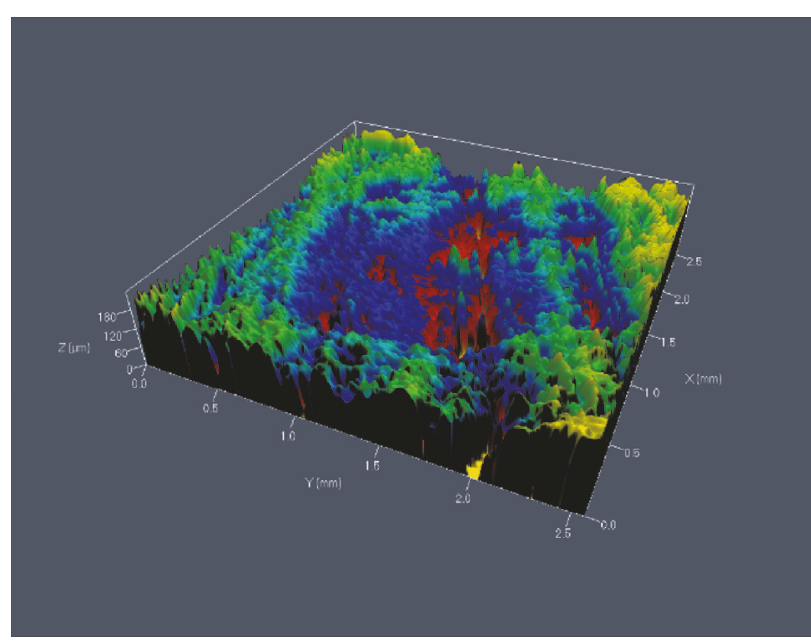

(a)

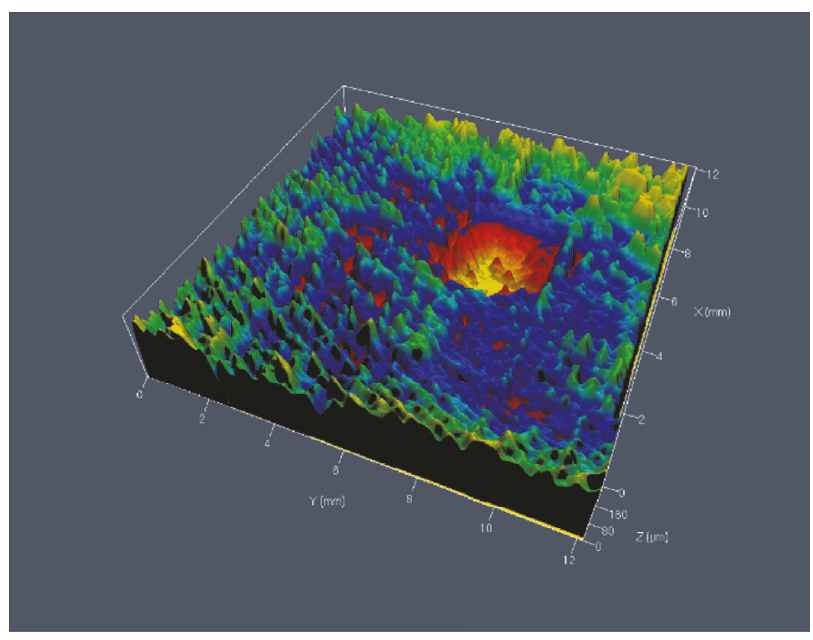

(c)

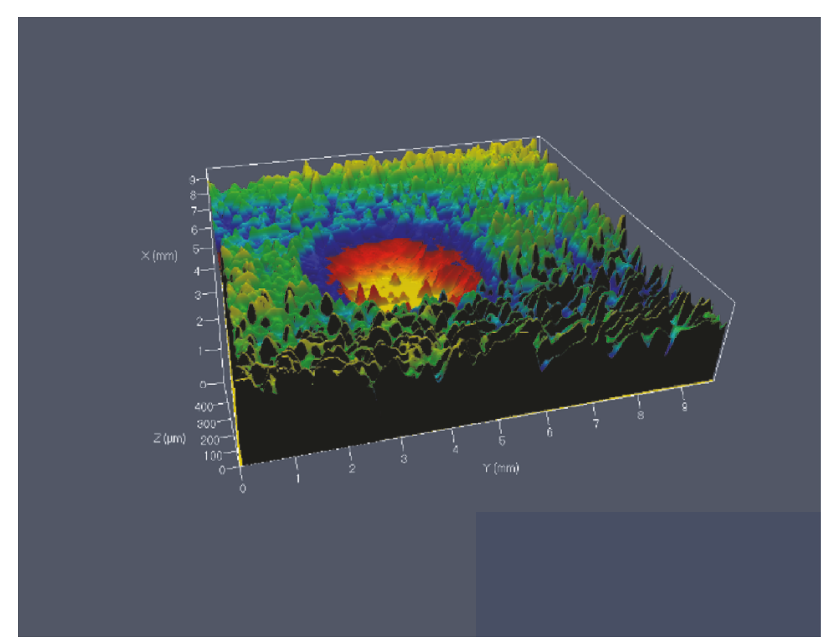

(b)

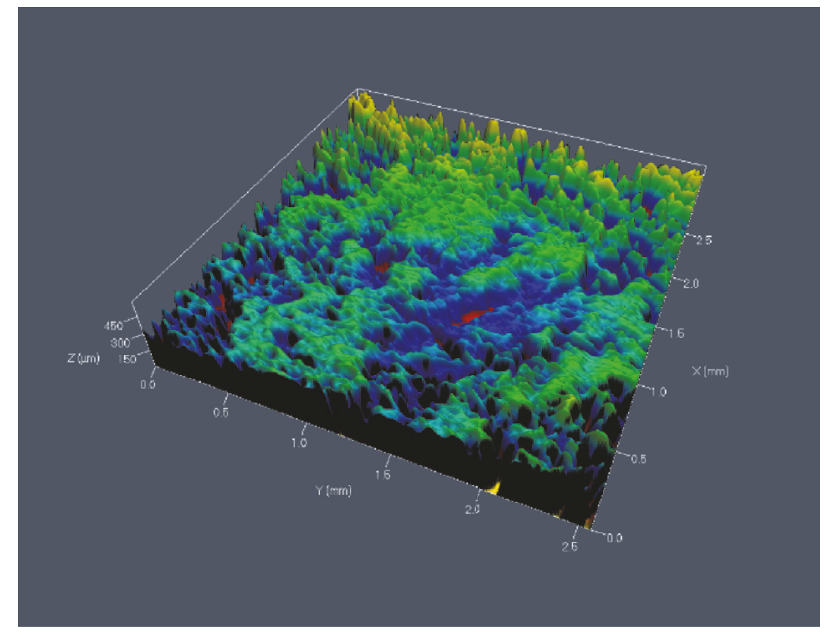

(d)

FIGURE 13: Worn surface in (a) polylactide w/o biocarbon, (b) polylactide with 5 vol.- $\%$ biocarbon, (c) polylactide with 15 vol.- $\%$ biocarbon, and (d) polylactide with 30 vol.- $\%$ biocarbon, LSM 700 ZEISS.

worn surfaces are summarized in Figure 14. According to the CLSM pictures, worn surface of unreinforced PLA has the highest wear depth and wear width. Unreinforced PLA exhibit the lowest wear resistance. Best wear resistance was observed for PLA with 30 vol.- $\%$. Evaluating the numbers of the measured wear volumes, reinforcement with biocarbon improves the general wear resistance under cycling sliding against an alumina ball. So the embrittlement and subsequent microcracking due to increased biocarbon content, as describe above under Section 3.3.1, may not contribute too much to the whole tribological system.

3.3.3. Friction Coefficients. Biocarbon addition is changing the sliding behaviour of the ceramic $\mathrm{Al}_{2} \mathrm{O}_{3}$ ball against the 3D printed biopolymer (Figure 15). There is a strong fluctuation of the coefficient of friction COF visible for unreinforced PLA due to the elastic recovery if the biopolymer. Following a run-in period during sliding of the $\mathrm{Al}_{2} \mathrm{O}_{3}$ ball against the $3 \mathrm{D}$ printed PLA body, the COF changes between 0.6 and 0.4. The fluctuation in friction is reduced due to the reinforcement with 5 and 30 vol.-\% biocarbon. However, there is still a cliffy variation of the COF for 15 vol.$\%$ reinforcement. The distribution of biocarbon particles appears homogeneous for filaments with 15 vol.- $\%$ or with 5 vol.- $\%$ biocarbon (Figures 1(b) and 1(c)). For the 30 vol.$\%$ biocarbon addition, the distribution of particles cannot be identified by stereomicroscopic observations. Although graphite belongs to solid lubricants, the friction behaviour of graphite is anisotropic in macroscopic and microscopic scale. It depends on atmosphere and loading. Kumar et al. [35] describe a load dependent nonlinear trend of friction coefficient in graphite when tested under ambient atmospheric conditions. At lower loading ranges, $\mathrm{COF}$ increases with load homogeneously. Kumar et al. explain these results with an increase in wear dimensions. Chemical structure of graphite does not change much and $3 \mathrm{D}$ graphite phase is maintained unaffected. Kumar et al. describe further that COF grows at higher normal load abruptly. They explain that 


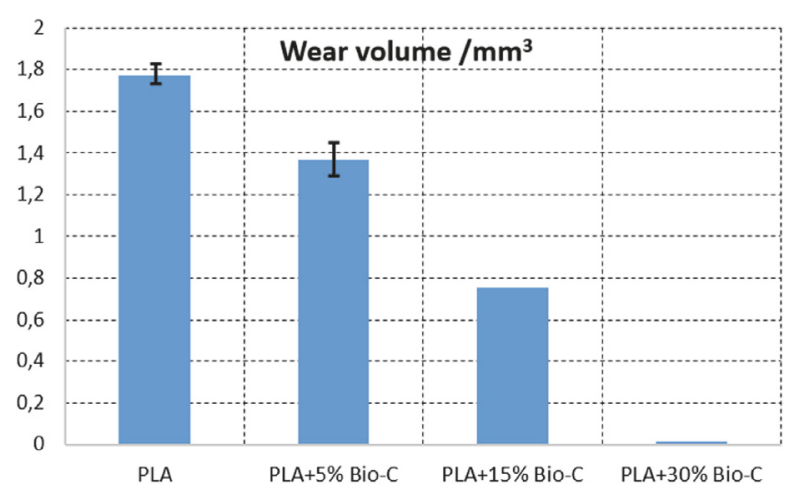

Figure 14: Wear volume of different PLA/biocarbon compounds produced by $3 \mathrm{D}$ printing in comparison to polylactide w/o biocarbon.

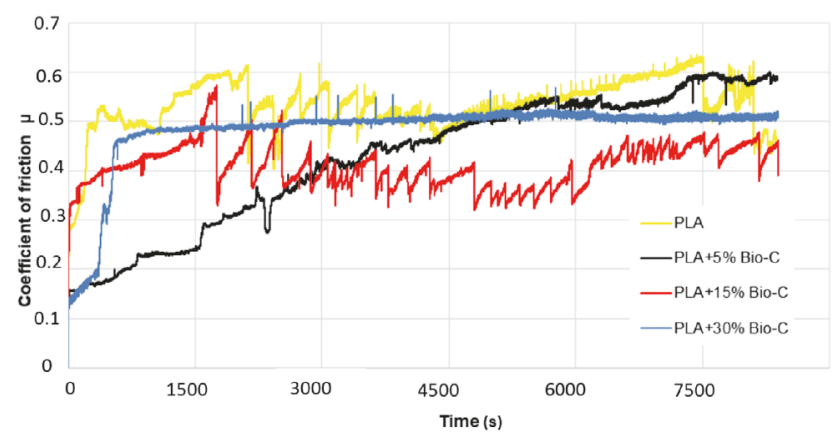

FIGURE 15: Coefficient of frictions COF of unreinforced polylactide PLA, PLA with 5 vol.- $\%$ biocarbon, and PLA with 15 vol.-\% of biocarbon and PLA with 30 vol.-\% of biocarbon.

sufficient high loads are able to transform 3D graphite into a 2D turbostratic phase. The later constitutes a high degree of stacking interlayer disorder and leads to the abrupt increase of $\mathrm{COF}$.

Sliding tests on graphite were carried out with a ceramic counterbodies like $\mathrm{Si}_{3} \mathrm{~N}_{4}, \mathrm{SiC}$, or $\mathrm{Al}_{2} \mathrm{O}_{3}$ balls by Radhika et al. [36]. Oxidation becomes stronger in case of sliding against $\mathrm{Al}_{2} \mathrm{O}_{3}$ ball as evident from XPS results obtained from the wear tracks.

Friction coefficients of graphite layers are around 0.2 and can reach 0.01 [35-37]. As mentioned before, the COF reaches values between 0.6 and 0.4 after a run-in phase, in the present study. Therefore, it can be concluded that the tribolayer is not determined by a graphitic sliding. The tribological behaviour is driven by the biopolymer. For the PLA/biocarbon composite with 30 vol.-\% biocarbon, a more smooth friction curve is seen. The fluctuations in COF are much lower in comparison to the other materials. This may be caused by a reduction of elastic recovery. The enhanced fraction of biocarbon could promote graphitic slipperiness. An improved stiffness due to the higher fraction of biocarbon may be advantageous as well. Although the value of friction is less fluctuating, it remains high, which points to the essential influence of the biopolymer on the sliding situation and no stable graphitic transfer films with reorientation of the graphite layers. In addition, low thermal conductivity could promote heat accumulation from the sliding motion which most probably effects oxidation of carbon and organic matrix.

Considering the visual appearance of the wear trace, the worn surface of the PLA reinforced with 30 vol.-\% biocarbon shows the before mentioned special feature. There are a lot of oval and roundish surface blowholes due to the $3 \mathrm{D}$ printing process. In fact, such dimples or voids are considered as disadvantageous defects. Within these dimples, the worn out particles seem to be accumulated (Figure 11), while the rest of the wear trace appears clear. The other worn surfaces reveal worn out particles as well, but they are distributed over the whole area due to lacking of dimples (surface blowholes). Not so for PLA reinforced with 30 vol.-\% biocarbon. The special surface topography of PLA reinforced with 30 vol.-\% biocarbon may be positive to ensure a stable $\mathrm{COF}$ and retard short- or long-term wear fatigue due to $\mathrm{COF}$ fluctuation.

\section{Conclusions}

The purpose of this work is to give general information about the structural and tribological properties of biocarbon reinforced PLA filaments for $3 \mathrm{D}$ printing and the parts printed using these filaments.

(i) Biocarbon was successfully integrated into the PLA. Good contact between biocarbon and PLA was observed by SEM. The interfacial strength should be proven in future work.

(ii) Four different filaments using polylactide (PLA) with varying loading levels of biocarbon from 0 vol.- $\%$ to 30 vol.- $\%$ by weight were produced.

(iii) A homogeneous distribution of biocarbon particles in the filaments was achieved. In biocomposites with 5 vol.- $\%$ of biocarbon the flat particles seemed to be oriented according to the longitudinal axis of the filaments. These effects may be explored more deeply in future work.

(iv) Using FDM technique, 4 samples with a standardized geometry (24 mm diameter and $7.8 \mathrm{~mm}$ high) were printed with different proportions of biocarbon reinforced filaments.

(v) The PLA sample produced with 30 vol.-\% carbon has been proven to show the lowest wear volume after dry sliding test against an $\mathrm{Al}_{2} \mathrm{O}_{3}$ ball. There were signs of different wear mechanism like fatigue wear or abrasion. Both mechanisms are influenced by the materials properties of the biocomposites, mainly by stiffness change and embrittlement due to the reinforcement.

(vi) Although the COF remains high at around 0.5, the friction values show less fluctuations in the case of reinforcement. COF is smooth and most homogeny for PLA with 30 vol.-\% biocarbon. However, it revealed the worst producibility during $3 \mathrm{D}$ printing with nozzle chocking. 
(vii) Biocarbon reinforced PLA applications are envisaged in automotive industry, i.e., in interior of green cars. Both biocarbon and PLA biopolymer are available from natural resources. An additional advantage is the favourable second use at the end of life of such a biogenic automotive components. Downcycling for usage as soil improving addition in agriculture is envisaged.

\section{Data Availability}

The data used to support the findings of this study are available from the corresponding author upon request.

\section{Conflicts of Interest}

The authors declare that they have no conflicts of interest.

\section{Acknowledgments}

The authors are thankful for financial support of the Project BUNT "Biogene Hochleistungskarbone" by the Thuringia Ministry TMWWDG, Germany. The fruitful scientific discussions during the symposium "Biomaterials \& Biogenic Materials" BM2, which took place for the first time on the $6^{\text {th }}$ of April 2018 in Schmalkalden, Germany, are deeply acknowledged as well.

\section{References}

[1] D. Notta-Cuvier, J. Odent, R. Delille et al., "Tailoring polylactide (PLA) properties for automotive applications: Effect of addition of designed additives on main mechanical properties," Polymer Testing, vol. 36, pp. 1-9, 2014.

[2] K. Madhavan Nampoothiri, N. R. Nair, and R. P. John, "An overview of the recent developments in polylactide (PLA) research," Bioresource Technology, vol. 101, no. 22, pp. 8493-8501, 2010.

[3] P. Mapleston, "Following the green line: bioplastics in Europe," Plastics Engineering Europe Winter, pp. 14-19, 2005.

[4] E. Olewnik-Kruszkowska, J. Nowaczyk, and K. Kadac, "Effect of ozone exposure on thermal and structural properties of polylactide based composites," Polymer Testing, vol. 56, pp. 299307, 2016.

[5] J. D. Badia, P. Reig-Rodrigo, R. Teruel-Juanes et al., "Effect of sisal and hydrothermal ageing on the dielectric behaviour of polylactide/sisal biocomposites," Composites Science and Technology, vol. 149, pp. 1-10, 2017.

[6] J. M. Murarriu and P. Dubois, "PLA compositers: From production to properties," Advanced Drug Delivery Reviews, vol. 107, pp. 17-46, 2016.

[7] J. D. Badia and A. Ribes-Greus, "Mechanical recycling of polylactide, upgrading trends and combination of valorization techniques," European Polymer Journal, vol. 84, pp. 22-39, 2016.

[8] J. T. Lee, M. W. Kim, Y. S. Song, T. J. Kang, and J. R. Youn, "Mechanical properties of denim fabric reinforced poly(lactic acid)," Fibers and Polymers, vol. 11, no. 1, pp. 60-66, 2010.

[9] S. C. Cifuentes, E. Frutos, R. Benavente, V. Lorenzo, and J. L. González-Carrasco, "Assessment of mechanical behavior of
PLA composites reinforced with Mg micro-particles through depth-sensing indentations analysis," Journal of the Mechanical Behavior of Biomedical Materials, vol. 65, pp. 781-790, 2017.

[10] S.-H. Su, Y. Huang, S. Qu, W. Liu, R. Liu, and L. Li, "Microdiamond/PLA composites with enhanced thermal conductivity through improving filler/matrix interface compatibility," Diamond and Related Materials, vol. 81, pp. 161-167, 2018.

[11] J. Holbery and D. Houston, "Natural-fiber-reinforced polymer composites in automotive applications," JOM: The Journal of The Minerals, Metals \& Materials Society (TMS), vol. 58, no. 11, pp. 80-86, 2006.

[12] X. Tian, T. Liu, C. Yang, Q. Wang, and D. Li, "Interface and performance of 3D printed continuous carbon fiber reinforced PLA composites," Composites: Part A, vol. 88, pp. 198-205, 2016.

[13] G. Agegnehu, A. K. Srivastava, and M. I. Bird, "The role of biochar and biochar-compost in improving soil quality and crop performance: A review," Applied Soil Ecology, vol. 119, pp. 156170, 2017.

[14] Y. Ding, Y. Liu, X. Huang et al., "Potential benefits of biochar in agriculture soils: A review, Pedosphere, vol. 27, no. 4, pp. 645661, 2017.

[15] M. Olmo, A. M. Lozano, V. Barrón, and R. Villar, "Spatial heterogeneity of soil biochar content affects soil quality and wheat growth and yield," Science of the Total Environment, vol. 562, pp. 690-700, 2016.

[16] X. He, Z. Liu, W. Niu et al., "Effects of pyrolysis temperature on the physicochemical properties of gas and biochar obtained from pyrolysis of crop residues," Energy, vol. 143, pp. 746-756, 2018.

[17] B. Zhao, D. O'Connor, J. Zhang et al., "Effect of pyrolysis temperature, heating rate, and residence time on rapeseed stem derived biochar," Journal of Cleaner Production, vol. 174, pp. 977-987, 2018.

[18] A. Yadav, K. B. Ansari, P. Simha, V. G. Gaikar, and A. B. Pandit, "Vacuum pyrolysed biochar for soil amendment," ResourceEfficient Technologies, vol. 2, pp. S177-S185, 2016.

[19] L. Wang, N. Alsaker, O. Skreiberg, and B. Hovd, "Effect of carbonization conditions on $\mathrm{CO} 2$ gasification reactivity of biocarbon," Energy Prodedia, vol. 142, pp. 932-937, 2017.

[20] Q. Wang, Y. Li, K. Wang et al., "Mass production of porous biocarbon self-doped by phosphorus and nitrogen for costeffective zinc-air batteries," Electrochimica Acta, vol. 257, pp. 250-258, 2017.

[21] A. Dorner-Reisel, Y. Yoseph, V. Matner, V. Klemm, and S. Svoboda, "Investigation of carbonation of wheat stems from central Europe during slow pyrolysis at different temperatures," Journal of Environmental \& Agriclture Research IJOEAR, vol. 3, no. 1, pp. 30-39, 2017.

[22] M. Kariz, M. Sernek, M. Obućina, and M. K. Kuzman, "Effect of wood content in FDM filament on properties of 3D printed parts," Materials Today Communications, vol. 14, pp. 135-140, 2018.

[23] P. K. Bajpai, I. Singh, and J. Madaan, "Tribological behavior of natural fiber reinforced PLA composites," Wear, vol. 297, no. 1-2, pp. 829-840, 2013.

[24] B. K. Goriparthi, K. N. S. Suman, and N. Mohan Rao, "Effect of fiber surface treatments on mechanical and abrasive wear performance of polylactide/jute composites," Composites Part A: Applied Science and Manufacturing, vol. 43, no. 10, pp. 18001808, 2012. 
[25] F. Rengier, A. Mehndiratta, H. von Tengg-Kobligk et al., "3D printing based on imaging data: review of medical applications," International Journal for Computer Assisted Radiology and Surgery, vol. 5, no. 4, pp. 335-341, 2010.

[26] X. Wang, M. Jiang, Z. Zhou, J. Gou, and D. Hui, “3D printing of polymer matrix composites: A review and prospective," Composites Part B: Engineering, vol. 110, pp. 442-458, 2017.

[27] X. Tian, T. Liu, C. Yang, Q. Wang, and D. Li, "Interface and performance of $3 \mathrm{D}$ printed continuous carbon fiber reinforced PLA composites," Composites Part A: Applied Science and Manufacturing, vol. 88, pp. 198-205, 2016.

[28] G. Irmer and A. Dorner-Reisel, "Micro-Raman studies on DLC coatings," Advanced Engineering Materials, vol. 7, no. 8, pp. 694705, 2005.

[29] A. C. Ferrari and J. Robertson, "Interpretation of Raman spectra of disordered and amorphous carbon," Physical Review B: Condensed Matter and Materials Physics, vol. 61, no. 20, pp. 14095-14107, 2000.

[30] M. J. Matthews, M. A. Pimenta, G. Dresselhaus, M. S. Dresselhaus, and M. Endo, "Origin of dispersive effects of the Raman D band in carbon materials," Physical Review B: Condensed Matter and Materials Physics, vol. 59, no. 10, pp. R6585-R6588, 1999.

[31] G. A. Zickler, B. Smarsly, N. Gierlinger, H. Peterlik, and O. Paris, "A reconsideration of the relationship between the crystallite size La of carbons determined by X-ray diffraction and Raman spectroscopy," Carbon, vol. 44, no. 15, pp. 3239-3246, 2006.

[32] Z. Wu, W. Yang, L. Chen, H. Meng, J. Zhao, and S. Wang, "Morphology and microstructure of co-pyrolysis char from bituminous coal blended with lignocellulosic biomass: Effects of cellulose, hemicellulose and lignin," Applied Thermal Engineering, vol. 116, pp. 24-32, 2017.

[33] R. Azargohar, S. Nanda, J. A. Kozinski, A. K. Dalai, and R. Sutarto, "Effects of temperature on the physicochemical characteristics of fast pyrolysis bio-chars derived from Canadian waste biomass," Fuel, vol. 125, pp. 90-100, 2014.

[34] Y. Shao, C. Guizani, P. Grosseau, D. Chaussy, and D. Beneventi, "Biocarbons from microfibrillated cellulose/lignosulfonate precursors: A study of electrical conductivity development during slow pyrolysis," Carbon, vol. 129, pp. 357-366, 2018.

[35] N. Kumar, A. T. Kozakov, T. R. Ravindran, S. Dash, and A. K. Tyagi, "Load dependent friction coefficient of crystalline graphite and anomalous behavior of wear dimension," Tribology International, vol. 88, pp. 280-289, 2015.

[36] R. Radhika, N. Kumar, R. Pandian, T. R. Ravindran, S. Dash, and A. K. Tyagi, "Structural transformation and friction behavior in turbostratic graphite sliding against $\mathrm{Si}_{3} \mathrm{~N}_{4}, \mathrm{SiC}$ and $\mathrm{Al}_{2} \mathrm{O}_{3}$ balls," Surface and Coatings Technology, vol. 253, pp. 300-306, 2014.

[37] G. Zhang, Y. Liu, F. Guo, X. Liu, and Y. Wang, "Friction characteristics of impregnated and non-impregnated graphite against cermentd carbide under water lubrication," Journal of Materials Science Technology, vol. 33, pp. 1203-1209, 2017. 


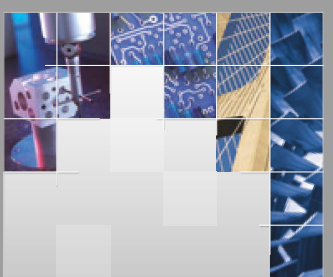

\section{Enfincering}
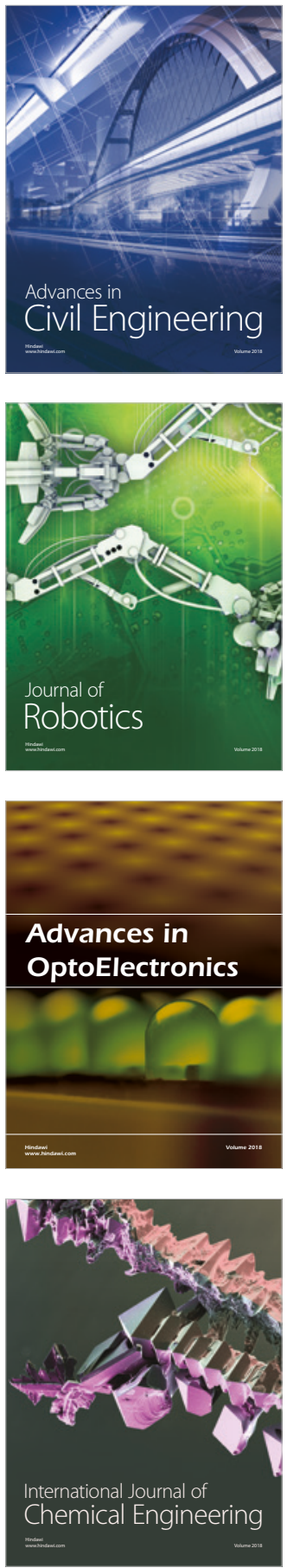

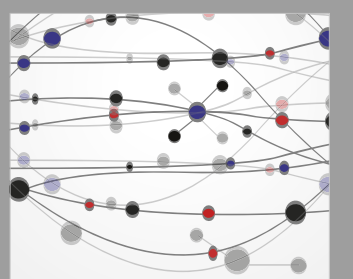

\section{Rotating \\ Machinery}

The Scientific World Journal

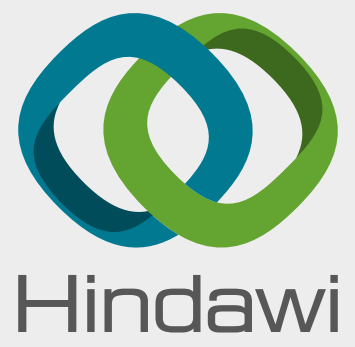

Submit your manuscripts at

www.hindawi.com
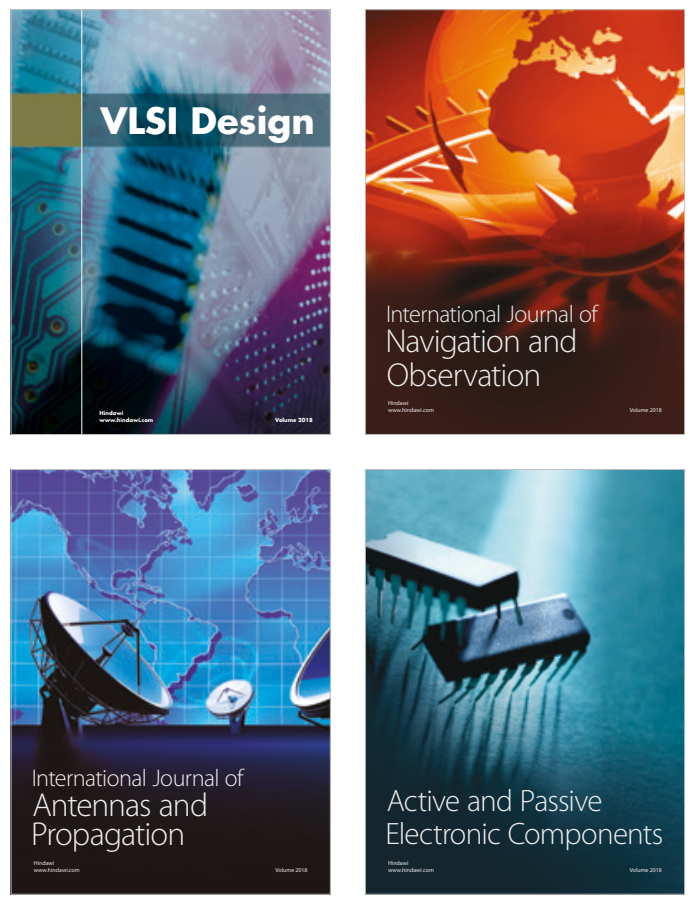
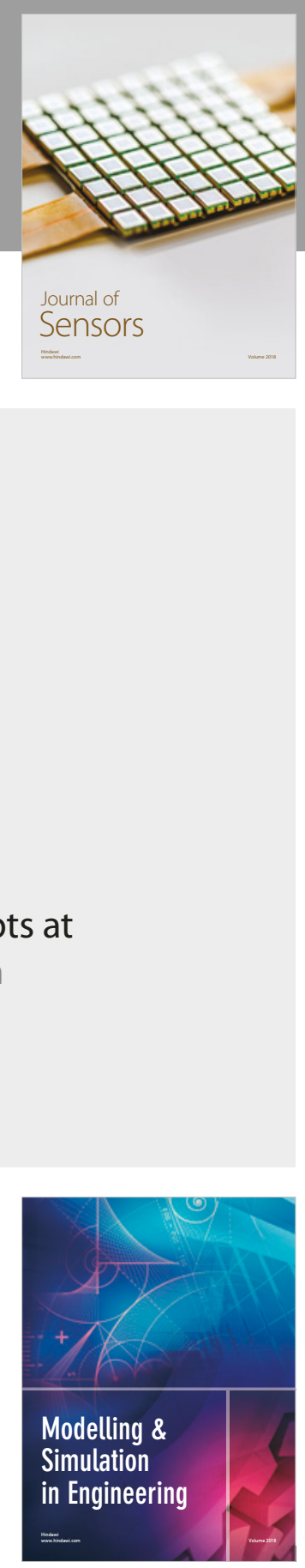

\section{Advances \\ Multimedia}
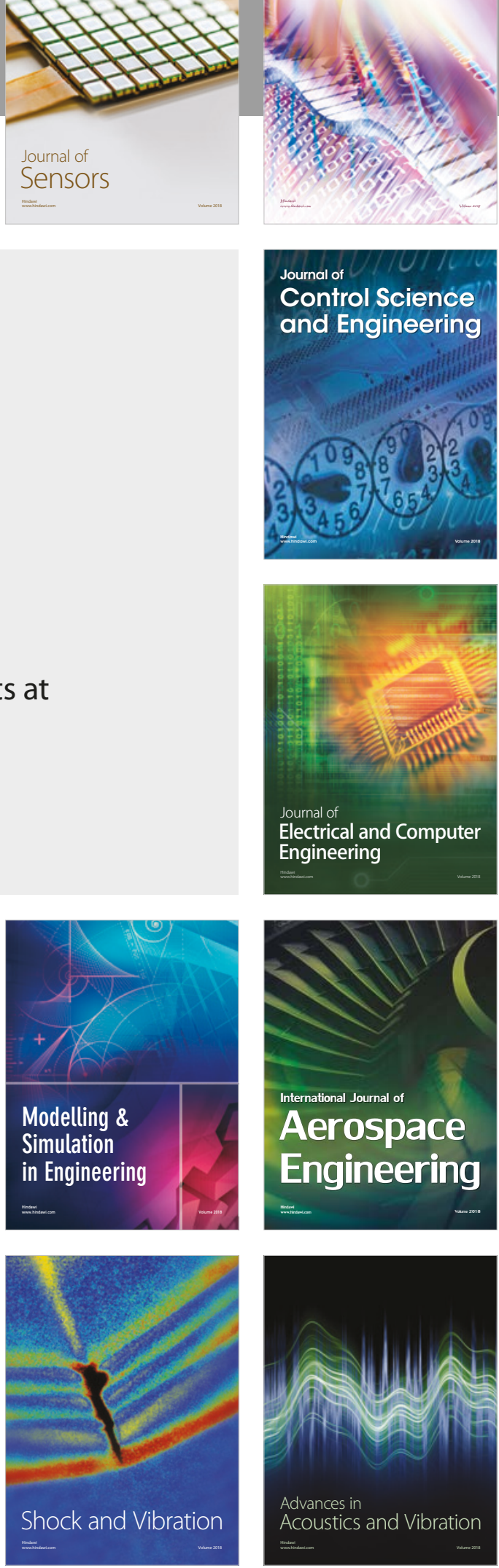